\title{
Pupillometric Assessment of Autonomic Nervous System in Children with Allergic Rhinitis
}

\author{
Mustafa Ozsutcu $^{\mathrm{a}}$ Emin Ozkaya $^{\mathrm{b}}$ Aysegul Demir $^{\mathrm{b}}$ Ufuk Erenberk $^{\mathrm{b}}$ \\ Ayhan Sogut $^{c}$ Rusen Dundaroz ${ }^{b}$ \\ Departments of a Ophthalmology and ${ }^{b}$ Pediatrics, Division of Pediatric Allergy, Bezmialem Vakif University, \\ Istanbul, and ' Department of Pediatrics, Division of Pediatric Allergy, Regional Education and Research Hospital, \\ Erzurum, Turkey
}

\section{Key Words}

Allergic rhinitis · Children · Pupil diameter · Autonomic nervous system

\section{Abstract}

Objective: The purpose of this study was to investigate autonomic nervous system dysfunction by measuring pupil sizes in pediatric patients with allergic rhinitis. Subjects and Methods: The study group consisted of 60 children (28 girls and 32 boys) who were age and gender matched with the control group, which also consisted of 60 children (26 girls and 34 boys). The diagnosis of allergic rhinitis was based on the history, physical examination and skin prick test performed by an allergologist. Pupil diameter measurements were performed using the pupillometer incorporated in the NIDEK OPD-Scan. Results: In the allergic rhinitis group, mean photopic and mesopic pupil diameters were $3.52 \pm 0.07$ and $5.98 \pm 0.21$, respectively, while in the control group, corresponding measurements were $4.03 \pm 0.18$ and $6.55 \pm 0.16$. There was a significant difference for photopic and mesopic pupil diameter between the groups ( $<0.001)$. Conclusion: This study showed that the pupil size in response to a light

\begin{tabular}{ll}
\hline KARGER & $\begin{array}{l}\text { ( } 2013 \text { S. Karger AG, Basel } \\
1011-7571 / 13 / 0225-0444 \$ 38.00 / 0\end{array}$ \\
E-Mail karger@karger.com & $\begin{array}{l}\text { This is an Open Access article licensed under the terms } \\
\text { of the Creative Commons Attribution-NonCommercial- } \\
\text { www.karger.com/mpp }\end{array}$ \\
$\begin{array}{l}\text { NoDerivs 3.0 License (www.karger.com/OA-license), appli- } \\
\text { cable to the online version of the article only. Distribution } \\
\text { for non-commercial purposes only. }\end{array}$
\end{tabular}

stimulus in children with allergic rhinitis was smaller than that of the control group and may indicate parasympathetic hyperactivity and sympathetic hypoactivity.

Copyright $\odot 2013$ S. Karger AG, Basel

\section{Introduction}

Allergic rhinitis is a chronic inflammatory disease of the upper airways characterized by sneezing, itching, nasal congestion and rhinorrhea $[1,2]$. Allergic rhinitis has become increasingly prevalent in the Middle East Gulf region; estimates indicate that up to $36 \%$ of the region's population may be affected [3]. The overall increased sensitivity to allergens has been attributed to rapid development, the oil industry, modernization with amenities such as carpeting and air-conditioning, and the introduction of nonnative species of plants and grass, all contributing to an overall increased sensitivity to allergens [4].

Although allergic rhinitis is defined as an inflammatory disorder of the upper airways, inflammation alone is not sufficient to explain the chronic nature of the disease. 
It is widely accepted that allergic rhinitis is a multifactorial disorder, in which one of the most important causal components is neurological involvement [5]. It has been found that the central nervous system plays an important role in the symptomology of hypersensitivity reactions, but the exact mechanism remains to be elucidated [6]. However, a probable mechanism has been attributed to changes in autonomic nervous system (ANS) activity [7, 8], particularly the sympathetic nervous system.

Pupillometry is a valid low-cost method for the evaluation of ANS activity. The pupil is controlled by two kinds of muscles whose innervations are different: the iris sphincter is innervated by the parasympathetic nervous system, while the dilator by the sympathetic nervous system. Therefore, pupillometry has a potential to allow independent evaluation of both types of ANS activity. $\mathrm{Pu}$ pillometry has been proven to be a useful tool in medical research and reveals the subclinical defects in the autonomic function of various diseases [9]. However, the relationship between allergic rhinitis and changes in pupillary size has not been studied in children. Therefore, the aim of this study was to investigate ANS activity by measuring pupil size in children with allergic rhinitis compared to healthy controls.

\section{Subjects and Methods}

\section{Ethical Approval}

The study was performed in accordance with the Declaration of Helsinki and Good Clinical Practice and was approved by the local Ethics Committee; all subjects and patients provided informed consent for participation.

\section{Study Population}

A total of 60 children aged 6-13 years who were newly diagnosed with persistent allergic rhinitis at the Pediatric Allergy Outpatient Unit of Bezmialem Vakif University Hospital, Istanbul, Turkey from May 2010 to May 2011 were included in the study. The diagnosis and severity of persistent allergic rhinitis were defined according to Allergic Rhinitis and its Impact on Asthma (ARIA) guidelines [10]. This group of patients qualified as having persistent allergic rhinitis if they had at least 2 rhinitis symptoms (sneezing, rhinorrhea, nasal obstruction and itching) at least 6 months of the year for the previous 2 years and also had a positive skin prick test response to at least 1 clinically significant perennial allergen (e.g. house dust mites, molds, cockroach, cockroach excrete or animal dander). None of these newly diagnosed children had received oral, inhaled or nasal corticosteroids or other medication in the 4 weeks prior to the study. Exclusion criteria were: (1) children presenting with clinical evidence of recurrent or active airway infection; (2) children diagnosed with concomitant asthma; (3) children with severe comorbidities, and (4) patients who had been treated with antibiotics, nasal vasoconstrictors, antihistamines or topical or systemic corticosteroids. Total
$\operatorname{IgE}$ and eosinophil counts were obtained, and skin testing was performed with a battery of 16 aeroallergens on the volar surface of the forearm.

The control group was composed of 60 age- and sex-matched children who presented during the same period to the outpatient department of the hospital. The control group presented with preoperative routine examination (e.g. inguinal hernia, tonsillectomy) or came for regular follow-up. The control patients were evaluated with regard to chronic and/or severe infections, rheumatological and autoimmune disorders, and familial and personal history of atopy. Children were included in the control group if they responded negatively to an established and validated allergic rhinitis questionnaire and if they had no personal and familial history of atopy and no signs of atopic disorder. All children in the control group underwent skin prick testing and had obtained total IgE and total eosinophil counts. In both groups, children using any ophthalmic medication (eye drops) or who had ophthalmic disorders such as refraction errors, esotropia or exotropia, as well as corneal and macular pathologies, were excluded.

\section{Diagnosis of Allergy}

The diagnosis of allergic rhinitis was based on the history, symptoms and skin prick test results performed by a pediatric allergologist (O.E.). The skin prick tests were performed using a routine procedure. Sixteen common aeroallergens with pollen found in the atmosphere, mites (Dermatophagoides farinae and Dermatophagoides pteronyssinus), molds, cockroach, cockroach excrete or animal dander were used. Skin prick tests were applied on the volar surface of the forearm by the same investigator (O.E.). Negative (50\% glycerin saline) and positive ( $0.1 \%$ histamine phosphate) controls were also performed. The skin tests were examined after $10 \mathrm{~min}$ and the resulting wheal and flare responses were measured. A test was considered positive if the wheal was $3 \mathrm{~mm}$ larger in diameter than the negative control wheal. Drugs that suppress the immediate-type skin tests such as antihistamines were discontinued 7 days prior to skin prick tests.

\section{Pupillometric Measurements}

Pupil diameter measurements were performed using the pupillometer incorporated in the NIDEK OPD-Scan III (NIDEK Co. Ltd., Gamagori, Japan) which uses an infrared detector to capture an image and provides pupillometric measurements. OPD-Scan automatically performs three measurements (first under mesopic conditions followed by one scan under photopic conditions) and yields the mean of these three measurements as an output. There is an automatic quality check which rejects bad measurements.

The pupil camera was used to capture images of each eye in a closed and darkened room with the illumination of $<0.07 \mathrm{~lx}$ in the afternoon (3:00-5:00 p.m.) under two natural undilated illumination conditions (mesopic: $10 \mathrm{~lx}$, photopic: $100 \mathrm{~lx}$ ). For this study all OPD measurements were performed after 15 min of dark adaptation for each eye $[11,12]$.

\section{Statistical Analysis}

Data were imported into Statistical Package for the Social Sciences (SPSS version 10.0) software for analysis. Continuous variables are expressed as mean \pm standard deviation. Independent samples t test was used for comparison of variables between the 
Table 1. Patient characteristics in the study and control groups

\begin{tabular}{lccl}
\hline & $\begin{array}{l}\text { Children } \\
\text { with allergic } \\
\text { rhinitis }\end{array}$ & $\begin{array}{l}\text { Control } \\
\text { group }\end{array}$ & p value \\
\hline Number of patients & 60 & 60 & \\
Age, years & $8.75 \pm 1.90$ & $8.86 \pm 1.86$ & 0.73 \\
Male, $\mathrm{n}(\%)$ & $32(53.3)$ & $34(56.6)$ & 0.46 \\
Height, cm & $132.0 \pm 3.3$ & $133.4 \pm 2.6$ & 0.63 \\
Weight, kg & $33.4 \pm 1.5$ & $32.8 \pm 1.7$ & 0.57 \\
IgE, kU/l & $356.7 \pm 42$ & $80.6 \pm 31$ & 0.024 \\
Body mass index & $14.52 \pm 3.0$ & $15.33 \pm 2.1$ & 0.46 \\
\hline
\end{tabular}

Values are given as mean \pm standard deviation, unless otherwise indicated

two groups. Pearson's correlation test was used to correlate symptom severity, total IgE and eosinophil counts, and pupil diameters (mesopic and photopic). Percent values were used for categorical and nominal data. $\mathrm{p}<0.05$ was considered significant.

\section{Results}

The mean age of the allergic rhinitis children was $8.75 \pm 1.90$ years and that of the controls was $8.86 \pm 1.86$ years with no significant difference for gender distribution between the groups ( $p>0.05$; table 1$)$. In the allergic rhinitis group, mean photopic and mesopic pupil diameters were $3.52 \pm 0.07$ (range: $3.24-4.33$ ) and $5.98 \pm 0.21$ (range: 5.46-6.46), respectively. In the control group, the corresponding values were $4.03 \pm 0.18$ (range: $3.73-$ 4.52 ) and $6.55 \pm 0.16$ (range: $6.12-7.43$ ). There was a significant difference for photopic and mesopic pupil diameter between the groups ( $\mathrm{p}<0.001$; fig. 1). A significant negative correlation was observed between the photopic and mesopic pupil diameter and nasal symptom scores $(r=-0.467, p<0.002)$. However, serum total IgE levels and eosinophil count were not significantly correlated with the photopic and mesopic pupil diameters in the patient group $(\mathrm{r}=0.06$ and 0.18 , respectively, $\mathrm{p}>0.05)$.

\section{Discussion}

Our study results showed that diameters of the pupil in response to intensity of light were found significantly decreased in children with allergic rhinitis. The main re-

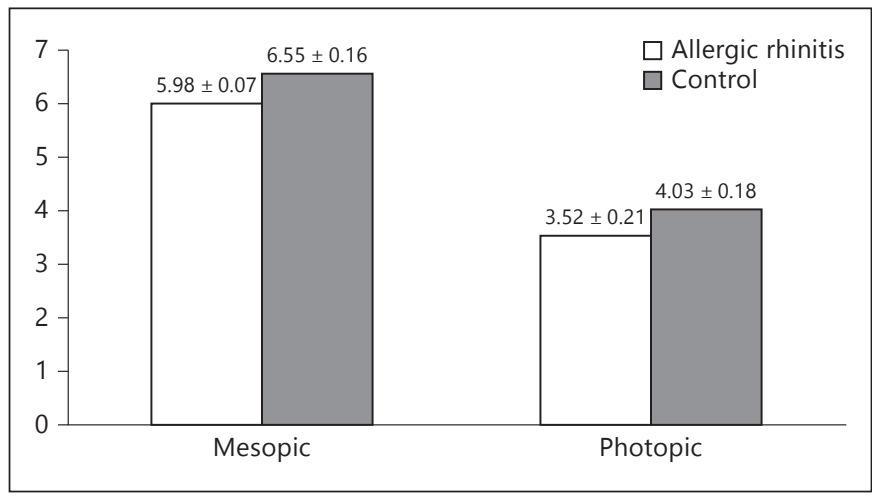

Fig. 1. Comparison of mesopic and photopic pupil sizes between the allergic rhinitis patients and healthy controls.

sults of our study are consistent with an increased vagal activity, and the greater constriction in pupil size in response to a light stimulus in allergic rhinitis children may indicate parasympathetic hyperactivity. This result implies parasympathetic hyperactivity and sympathetic withdrawal in children with allergic rhinitis. Although in the absence of a documented peripheral disorder the contribution of peripheral structures to the pupil reflex and regulation is negligible in comparison to that of central structures, this method is an indirect way of evaluating autonomic system function. Furthermore, there are some other factors that may change the pupil size other than autonomic state. For example, in an allergic condition, the sensory nerve system reaction causes secretion of neuropeptide that stimulates gland secretion of mucous at the local tissue, and at the same time may change the pupil diameter.

Many disorders in humans have been suspected to be related to or caused by ANS abnormalities such as allergic diseases [13-15]. It has been reported that the central nervous system plays an important role in the symptomology of hypersensitivity reactions, but the exact mechanism remains to be elucidated [6]. Although there are some studies examining the association between ANS dysfunction and allergic disease [14, 15], we could not find any report about pupillometric assessment in children with allergic rhinitis.

Neural involvement in allergic rhinitis has been investigated previously $[7,16,17]$. Ishman at al. [16] identified sympathetic hypofunction in allergic rhinitis. Afferent nerves, derived from the trigeminal ganglion and postganglionic autonomic nerves, innervate the nose. These afferent nerves act as a regulator of the air-condi- 
tioning function of the nose. Shahabi et al. [18] hypothesized that atopic diseases decrease sympathetic tone in all tissues except in the site of allergic reaction and secondary lymphoid organs via the cytokines which were secreted by T helper subtype 2 cells.

In a study by Kaliner et al. [19], all allergic subjects showed abnormal beta-adrenergic hyporeactivity and cholinergic hypersensitivity, whereas allergic asthma was singularly associated with excessive alpha-adrenergic responsiveness. In a study by Tascilar et al. [20], sympathetic withdrawal and parasympathetic predominance was found in pediatric patients with allergic rhinitis. However, Ko et al. [21] showed that total nasal airflow was significantly decreased and the total nasal airway changes were significantly correlated with central autonomic system response in patients with allergic rhinitis. Emin et al. [22] found parasympathetic predominance and sympathetic hypofunction in allergic rhinitis by measuring sympathetic skin response and heart rate variation. Our study showed that pupillometric measurement, which mainly reflects parasympathetic nervous system activity, was increased in children with allergic rhinitis.

Pupil size is under the control of both sympathetic and parasympathetic autonomic fibers and is responsive to a range of excitatory stimulus properties. Therefore, pupillometric measurements can provide valuable data concerning the functioning of both branches of the ANS. Furthermore, the pupillometric approach is a simple noninvasive technique to obtain relevant information on the ANS. Our study was performed to evaluate the role of autonomic dysregulation on allergic rhinitis by measur- ing pupil sizes under photopic and mesopic lighting conditions using the pupillometer. It has been long known that constriction of the pupil to a light flash depends on parasympathetic outflow from the Edinger-Westphal nucleus. Lowenstein and Loewenfeld [23] employed pharmacological agents and surgical ablation to study the pupillary light reflex in cats and monkeys and described two phases of constriction and primary and secondary redilatory phases. They hypothesized that the constrictive phases were due to a parasympathetic activation modified at its conclusion by a superimposed central sympathetic inhibition of the Edinger-Westphal nucleus. The primary redilation was thought to be due to parasympathetic relaxation, while the secondary redilation was thought to be due to an increase in peripheral sympathetic activity. Observations in a small number of patients with neurological lesions suggest that this model may also apply in humans $[24,25]$.

\section{Conclusion}

Our results provide evidence of increased autonomic dysfunction in patients with allergic rhinitis. Our finding was that there was a lower mesopic and photopic pupil diameter in patients with allergic rhinitis compared to healthy subjects. Dynamic pupillometry is an easier, cheaper and faster technique than conventional autonomic function tests and requires minimal specialist training. As a result, pupillometric measurements may be a useful tool in evaluating autonomic dysfunction in patients with allergic rhinitis.

\section{References}

$\checkmark 1$ Skoner DP: Allergic rhinitis: definition, epidemiology, pathophysiology, detection and diagnosis. J Allergy Clin Immunol 2001; 108:S2-S8.

2 Ibiapina CC, Sarinho ES, Camargos PA, et al: Allergic rhinitis: epidemiological aspects, diagnosis and treatment. J Bras Pneumol 2008; 34:230-240.

- 3 Behbehani N, Arifhodzic N, Al-Mousawi M, et al: The seasonal variation in allergic rhinitis and its correlation with outdoor allergens in Kuwait. Int Arch Allergy Immunol 2004;133: 164-167.

4 Civelek E, Yavuz ST, Boz AB, et al: Epidemiology and burden of rhinitis and rhinoconjunctivitis in 9- to 11-year old children. Am J Rhinol Allergy 2010;24:364-370.
5 Canning BJ: Neurology of allergic inflammation and rhinitis. Curr Allergy Asthma Rep 2002;2:210-215.

6 Undem BJ, Kajekar R, Hunter DD, et al: Neural integration and allergic disease. J Allergy Clin Immunol 2000;106:S213-S220.

7 Mills JE, Widdicombe JG: Role of the vagus nerves in anaphylaxis and histamine-induced bronchoconstrictions in guinea-pigs. $\mathrm{Br} \mathrm{J}$ Pharmacol 1970;39:724-731.

8 Baraniuk JN, Silver PB, Kaliner MA, et al: Effects of ipratropium bromide on bradykinin nasal provocation in chronic allergic rhinitis. Clin Exp Allergy 1994;24:724-729.

-9 Dundaroz R, Turkbay T, Erdem U, et al: Pupillometric assessment of autonomic nervous system in children with functional enuresis. Int Urol Nephrol 2009;41:231-235.
10 Brozek JL, Baena-Cagnani CE, Bonini S, et al: Methodology for development of the Allergic Rhinitis and Its Impact on Asthma guideline 2008 update. Allergy 2008;63:38-46.

11 Gavriysky VS: Human pupillary light reflex during and after two-fold Valsalva maneuver. J Auton Nerv Syst 1995;54:247-252.

12 Fotiou F, Fountoulakis KN, Goulas A, et al: Automated standardized pupillometry with optical method for purposes of clinical practice and research. Clin Physiol 2000;20:336-347.

13 Tascilar E, Yokusoglu M, Dundaroz R, et al: Cardiac autonomic imbalance in children with allergic rhinitis. Tohoku J Exp Med 2009; 219:187-191.

14 Yokusoglu M, Ozturk S, Uzun M, et al: Heart rate variability in patients with allergic rhinitis. Mil Med 2007;172:98-101.
Pupillometric Assessment of Autonomic Nervous System
Med Princ Pract 2013;22:444-448 DOI: $10.1159 / 000350292$ 
15 Cicek D, Kandi B, Berilgen MS, et al: Does autonomic dysfunction play a role in atopic dermatitis? Br J Dermatol 2008;159:834-838.

16 Ishman SL, Martin TJ, Hambrook DW, et al: Autonomic nervous system evaluation in allergic rhinitis. Otolaryngol Head Neck Surg 2007;136:51-56.

17 Canning BJ: Neurology of allergic inflammation and rhinitis. Curr Allergy Asthma Rep 2002;2:210-215.

18 Shahabi S, Hassan ZM, Jazani NH, et al: Sympathetic nervous system plays an important role in the relationship between immune mediated diseases. Med Hypotheses 2006;67:900-903.
19 Kaliner M, Shelhamer JH, Davis PB, et al: Autonomic nervous system abnormalities and allergy. Ann Intern Med 1982;96:349-357.

20 Tascilar E, Yokusoglu M, Dundaroz R, et al: Cardiac autonomic imbalance in children with allergic rhinitis. Tohoku J Exp Med 2009; 219:187-191.

21 Ko JH, Kuo TB, Lee GS: Effect of postural change on nasal airway and autonomic nervous system established by rhinomanometry and heart rate variability analysis. Am J Rhinol 2008;22:159-165.

22 Emin O, Esra G, Ufuk E, et al: Autonomic dysfunction and clinical severity of disease in children with allergic rhinitis. Int J Pediatr Otorhinolaryngol 2012;76:1196-2000.
23 Lowenstein O, Loewenfeld IE: Mutual role of sympathetic and parasympathetic in shaping of the pupillary reflex to light. Arch Neurol Psychiatry 1950;64:341-377.

24 Lowenstein O: Clinical diagnosis of disturbances of the central sympathetic system by means of pupillography. Arch Neurol Psychiatry 1946;55:682-695.

25 Lowenstein O, Friedman ED: Pupillographic studies. I. Present state of pupillography: its method and diagnostic significance. Arch Ophthalmol 1942;27:969-982. 